\title{
Maternal and perinatal outcome in cardiac disease complicating pregnancy
}

\author{
Krupa R. Mange, Vidyadhar B. Bangal*
}

\begin{abstract}
Department of Obstetrics and Gynecology, Rural Medical College, Pravara Institute of Medical Sciences, Loni,
\end{abstract} Ahmednagar, Maharashtra, India

Received: 18 November 2020

Accepted: 17 December 2020

\section{*Correspondence:}

Dr. Vidyadhar B. Bangal,

E-mail: vbb217@ rediffmail.com

Copyright: (c) the author(s), publisher and licensee Medip Academy. This is an open-access article distributed under the terms of the Creative Commons Attribution Non-Commercial License, which permits unrestricted non-commercial use, distribution, and reproduction in any medium, provided the original work is properly cited.

\section{ABSTRACT}

Background: Maternal cardiac disease associated with pregnancy is considered as a high-risk pregnancy. Various physiological and hemodynamic alterations during the course of pregnancy make these women prone for various complications and related morbidity and mortality.

Methods: A prospective cross-sectional study of 105 cases of pregnancy complicated by cardiac disease, reporting to tertiary care hospital for delivery, was carried out to find out the maternal and perinatal outcome.

Results: The incidence of cardiac disease in pregnancy in the present study was $0.54 \%$. Most of the women $(91 \%)$ belonged to low socioeconomic class. Rheumatic heart lesions constituted $87 \%$ of the cases. Mitral stenosis alone or in combination, was the commonest (57\%) valvular lesion. Incidence of spontaneous vaginal delivery was 53 percent and for ventose or outlet forceps was 12 percent. Incidence of caesarean section was $35 \%$. There were 2 maternal deaths, one each due to complication like pulmonary oedema and atrial fibrillation. The perinatal mortality was 36 per 1000 live births, mainly due to combination of factors like prematurity, low birth weight, neonatal sepsis and birth asphyxia.

Conclusions: Early diagnosis of heart disease, regular antenatal checkup, institutional delivery, limiting family size can reduce the maternal and perinatal mortality and morbidity associated with heart disease.

Keywords: Cardiac disease in pregnancy, Rheumatic heart disease, Maternal mortality

\section{INTRODUCTION}

Maternal cardiac disease associated with pregnancy is considered as a high-risk pregnancy. Various physiological and hemodynamic alterations during the course of pregnancy make these women prone for various complications and related morbidity and mortality. As such, hemodynamic changes during normal pregnancy are well tolerated by women with normal cardiac reserve. Diseased heart shows signs of de compensation with resultant increase in morbidity and mortality. Fetal health depends upon an adequate and continuous supply of welloxygenated maternal blood. In uncompensated heart disease, the oxygen supply becomes limited and that result in compromised fetal growth. There can be growth restriction, premature birth or may even fetal death.

Cardiac lesions are usually secondary to streptococcal rheumatic infection during childhood. It still remains as the commonest etiological factor for heart disease complicating pregnancy. It is because of frequent and repeated streptococcal infections in areas with poor sanitary conditions. In many pregnant women, heart disease still remains undiagnosed until complications develop. Even after the diagnosis, many women do not comply with the instructions given by obstetrician for various reasons. Women having additional obstetrical complications further worsen the prognosis. In western countries, maternal heart disease complicates $1-3 \%$ of 
pregnancies and is the third common cause of maternal death during pregnancy. ${ }^{1-3}$

Heart disease is one of the 3 major indirect causes of maternal mortality in India. Most data concerning pregnancy course in heart disease patients are anecdotal reports or are in small series; only a few comprehensive studies are available. ${ }^{4-9}$ The primary objective of the present study was to study the incidence of the different cardiac lesions during pregnancy and to assess the effect of heart disease on maternal and fetal health.

\section{METHODS}

This prospective cross-sectional study was conducted for 2 years period from January 2018 to December 2019 at Pravara rural hospital, which is a tertiary care center in Ahmednagar district. All pregnant women with diagnosed cardiac disease, who were admitted either in antenatal ward, intensive care unit or in labour room were enrolled in the study. Cardiologist's opinion was taken regarding cardiac status and safety of women during pregnancy and delivery or caesarean section. Joint management by physician and obstetrician was undertaken, whenever required. Detailed medical and obstetric history, keeping in mind the cardiac lesion was gathered through interview during first visit to hospital or labour room. Thorough clinical examination was performed to find out the type of cardiac lesion, any signs of failure, fetal wellbeing, duration of pregnancy. The case was then investigated with specific investigations to confirm the cardiac lesion and the cardiac functional status. Cases were graded as per NYHA classification. They were explained about the importance of rest, medication and regular antenatal visits. In every visit, physician was consulted for their opinion regarding cardiac status. Patients were told to have compulsory institutional delivery. Unregistered cases who reported to labour room were managed as per the cardiac status. Patients were kept for 8-10 days after delivery and were discharged with advice about contraception, breast feeding and antibiotic prophylaxis and cardiac surgery, if needed.

\section{RESULTS}

The total no of patients admitted for delivery during the study period were 19,408 . This included 105 cases of cardiac disease with different types of lesions. Thus, the incidence of cardiac disease in pregnancy was $0.54 \%$.

It was observed that, out of 105 cases studied,73\% were booked. The maximum patients were in the age group of 21 to 30 years $(88 \%)$ and few were in the age group of 15 to 20 years $(8.5 \%)$. The youngest patient was 18 years old and the oldest patient was of 37 years. Most of the women $(91 \%)$ belonged to lower socioeconomic class. Distribution of cases as per timing of registration revealed that $73 \%$ women were registered during pregnancy.
In the present study, Rheumatic cardiac lesions constituted $87 \%$ of the cases, $47 \%$ women had isolated mitral stenosis, $17 \%$ percent women had mitral stenosis and pulmonary hypertension, and $8.5 \%$ each had either mitral regurgitation or combine mitral regurgitation and mitral stenosis. It was observed that $43,32,14$ and $11 \%$ cases presented with NYHA grade 1 to 4 respectively. Mitral stenosis was the commonest heart lesion in $47 \%$ of the lesion.

Incidence of spontaneous vaginal delivery was $53 \%$ and ventose or outlet forceps were carried out in 12 percent cases. The average duration of labor was 5 hours in multigravida and 6-8 hours in primigravidae. One patient had atonic post-partum haemorrhage, which was managed with medical methods. Incidence of caesarean section was $35 \%$. Common indications of caesarean section were NYHA grade 3 and 4 lesions, associated abnormal presentations, multi-fetal pregnancy, previous two caesarean sections, fetal distress, postdated pregnancy and caesarean on demand.

There were 2 maternal deaths, one each due to complications like pulmonary oedema and atrial fibrillation. It was observed that the incidence of Lowbirth-weight babies was $61 \%$ among the women who had cardiac lesion. The perinatal mortality was 36 per 1000 live births, mainly due to combination of factors like prematurity, low birth weight, neonatal sepsis and birth asphyxia.

\section{DISCUSSION}

Over last few decades, the percentage of women with cardiac disease, who reach childbearing age, has increased due to the improved diagnostic and treatment facilities. As a result, these women get an opportunity to have their reproductive career. The majority of the patients $(67 \%)$ were either primigravidae or primipara. In the present study, $73 \%$ cases were registered during antenatal period. This shows good awareness among the community and better referral services from government and private practitioners to tertiary care hospital. Rheumatic heart lesions constituted $87 \%$ of the cases.

The incidence of RHD is higher, as most of the patients belonged to low socioeconomic class where poverty, poor nutrition, low level of sanitation and hygiene and inaccessibility to health services was common. Isolated mitral stenosis were the commonest heart lesion in $47 \%$ of the lesion. Most patients (42.8\%) belonged to grade I functional heart disease and $31.4 \%$ of the cases belong to grade II heart disease. There were 10 cases with a history of mitral valvotomy done within 2 years before conception. They stood the pregnancy very well and delivered spontaneously at term without any complications. The puerperium was also uneventful.

There were 6 cases of cardiac failure. Cardiac failure occurred most commonly between 28 to 36 weeks of 
gestation. Only one patient developed failure during puerperium. There were two maternal deaths. Both these women were unregistered multi-gravida with multiple valve involvement. They reported in labour with cardiac failure and arrhythmia. The perinatal mortality was 36 per 1000 live births.

Accurate assessment of the individual maternal and fetal risk during pregnancy is of fundamental importance for optimal patient outcome. Despite the diversity and broad morphological and functional variability of heart diseases, few predictors for complications during pregnancy have been recently described. In a prospective multicenter study enrolling 562 women with heart disease monitored in 13 Canadian hospitals, Siu et al identified poor functional NYHA class or cyanosis, left ventricular systolic dysfunction, and left heart obstruction as major determinants for maternal cardiac complications. ${ }^{6}$ In the clinical setting, this classification proved to be basically useful and enabled reliable assessment not only of maternal but also of fetal/neonatal risk. Review of the literature indicates that mortality among minimally symptomatic pregnant women with cardiac disease is about $1 \%$ : i.e., within the range of the incidence among the healthy general population. ${ }^{10,11}$ In contrast, pregnant women with severe symptoms have been reported to experience a mortality risk up to 5$15 \% .^{12}$

\section{CONCLUSION}

Cardiac disease complicating pregnancy is a high-risk situation and demands special attention throughout pregnancy. An expert supervision and management by the obstetrician, cardiologist or physician and the fullest co-operation by the patient throughout antenatal, intranatal and post-natal period, results in achieving the optimum maternal and perinatal outcome. It is essential to educate the rural population about the importance of regular antenatal visits and institutional delivery. Establishing the facility for cardiac surgery at affordable cost in rural area will certainly go a long way in decreasing the mortality, morbidity related to cardiac disease complicating pregnancy.

\section{Funding: No funding sources} Conflict of interest: None declared

Ethical approval: The study was approved by the Institutional Ethics Committee

\section{REFERENCES}

1. Arafeh JM, Baird SM. Cardiac disease in pregnancy. Crit Care Nurs Q. 2006;29:32-52.

2. Dobbenga-Rhodes YA, Prive AM. Assessment and evaluation of the woman with cardiac disease during pregnancy. J Perinat Neonatal Nurs. 2006;20:29530 .

3. Stangl V, Baumann G, Stangl K. Pregnancy risks in acquired heart diseases. Z Kardiol. 2001;90:16-29.

4. Avila WS, Rossi EG, Ramires JA. Pregnancy in patients with heart disease: experience with 1000 cases. Clin Cardiol. 2003;26:135-14.

5. Siu SC, Sermer M, Harrison DA, Nunes Md, Rezende CA. Risk and predictors for pregnancyrelated complications in women with heart disease. Circulation. 1997;96:2789-94.

6. Siu SC, Sermer M, Colman JM, Nunes Md, Rezende CA. Prospective multicenter study of pregnancy outcomes in women with heart disease. Circulation. 2001;104:515-52.

7. Siu SC, Colman JM, Sorensen S. Adverse neonatal and cardiac outcomes are more common in pregnant women with cardiac disease. Circulation. 2002;105:2179-84.

8. Abdel-Hady ES, El-Shamy M, El-Rifai AA, AbdelSamad A, Moussa S. Maternal and perinatal outcome of pregnancies complicated by cardiac disease. Int J Gynaecol Obstet. 2005;90:21-5.

9. Khairy P, Ouyang DW, Fernandes SM, Lee-Parritz A, Economy KE. Pregnancy outcomes in women with congenital heart disease. Circulation. 2006;113:517-24

10. Clark SL. Cardiac disease in pregnancy. Crit Care Clin. 1991;7:777-97.

11. Barbosa PJ, Lopes AA, Feitosa GS, Almeida RV, Almeida RV, Brito JC et al. Prognostic factors of rheumatic mitral stenosis during pregnancy and puerperium. Arq Bras Cardiol. 2000;75:215-24.

12. Sawhney H, Aggarwal N, Suri V, Vasishta K, Sharma Y, Grover A et al. Maternal and perinatal outcome in rheumatic heart disease. Int $\mathbf{J}$ Gynaecol Obstet. 2003;80:9-14.

Cite this article as: Mange KR, Bangal VB.

Maternal and perinatal outcome in cardiac disease complicating pregnancy. Int J Reprod Contracept Obstet Gynecol 2021;10:559-61. 